\title{
Introduction and overview of the symposium issue: innovations and intellectual property values
}

\author{
Pierre Mohnen
}

Published online: 22 December 2007

(C) The Author(s) 2007

The eight papers included in this symposium issue are revised versions of presentations made at the AEA ("Association d'Économétrie Appliquée") Conference on "Innovations and Intellectual Property Values" that took place in Paris on October 20-21, 2005.

The eight papers have one thing in common. They all use micro data on intangibles or technology indicators, but of a very different kind (licensing-out contracts, royalty payments, innovation activities, patent renewal fees, patent citations, settlements in infringement suits, and R\&D spillovers), showing the wide scope of the economics of innovation and intellectual property values and the richness of the data that are used in empirical studies in this area.

Five papers deal directly with the evaluation or the effects of intellectual property rights. Two papers, by Sadao Nagaoka and by Ryuhei Wakasugi and Banri Ito, examine whether the strength of intellectual property rights ease technology transfer, in particular from developed to developing countries. Two papers, by Charlotta Grönqvist and by Emanuele Bacchiocchi and Fabio Montobbio, estimate the value of patents. The former estimates the value and the rate of decay in the revenues of patents using patent renewal data. The latter estimates the value of patents using patent citation data. One paper, by Katrin Cremers, examines one aspect of patent infringement suits, namely the determinants of the chances of reaching an early settlement before a final judgement is rendered by the patent courts.

Four papers deal with technology transfer in a broad sense. Three papers estimate the extent and the channels of knowledge spillovers across firms (spatial proximity or technological proximity in Luigi Aldieri and Michele Cincera, mobility of inventors in Karin Hoisl, and patent citations in Emanuele Bacchiocchi and Fabio Montobbio). One paper, by Bettina Peters, evaluates the temporal dimension of knowledge transmission, namely the persistence of innovation within a firm.

All papers have policy implications. The issue of strength of patent protection is of central importance to the ultimate success of the TRIPS (Trade Related Intellectual Property Rights) agreements in the present free trade negotiations. As Charlotta Grönqvist mentions, her results have at least three implications for policy making. First, because of

P. Mohnen $(\bowtie)$

UNU-MERIT and University of Maastricht, P.O. Box 616, Maastricht 6200 MD, The Netherlands

e-mail: p.mohnen@merit.unimaas.nl 
the patent skewness, patent counts are not a good measure of innovation output unless they are corrected by their relative value, as for instance estimated in her paper or with the help of forward patent citations. Second, the assumption often made in models of optimal patent design, that broad patents are more valuable than narrow patents, is not consistent with the results on the Finnish data. Third, the patent value varies across technologies and applicants, putting into question the "one size fits all" recommendation of patent protection. The argument is often made that in Europe patent protection is hard to implement because of different national patent courts. Within this discussion around the necessity of a European patent court it is interesting to observe, as shown in the paper by Katrin Cremers, that even within a given judicial system there are differences in the settlement dynamics between two distinct district courts. Emanuele Bacchiocchi and Fabio Montobbio caution against the emulation of the Bayh-Dole act in Europe on the ground that university patents are not superior to corporate patents and that universities collaborate anyway with companies, producing the inventions but giving the ownership to companies. The four papers on spatial and temporal knowledge spillovers have implications for the measurement of the returns to $R \& D$ investments and the evaluation of technology policies. $R \& D$, invention or innovation stimulations can have long-lasting and far-reaching secondary effects. Spillovers can be seen as unintended forms of technology transfer.

The remainder of this article will summarize each of the eight papers. A synthetic overview of the whole issue is given in Table 1.

\section{Sadao Nagaoka}

Sadao Nagaoka uses data on licensing-out contracts of Japanese firms listed on the Tokyo stock exchange to test two hypotheses that are derived from a model of royalty maximisation with endogenous ownership control (independent, related, or subsidiary) and endogenous licensing choice (patent licensing, know-how licensing, or dual licensing). ${ }^{1}$ The emphasis is on the effect of patent protection in host countries on the type of technology transfer and the type of ownership control by Japanese firms. Hypothesis 1 states that the relative incidence of know-how licensing as a whole (i.e. pure know-how or dual licensing) relative to pure patent licensing will in general decrease with the level of patent protection; it will increase only if the switch from no licensing to dual licensing is very substantial. Hypothesis 2 states that the ownership control declines with the level of patent protection when the contract covers the patent right. It is not affected if the contract covers only know-how. Both hypotheses are confirmed empirically with cross-sectional data on licensing of Japanese firms to other firms in 50 odd countries.

\section{Ryuhei Wakasugi and Banri Ito}

A similar question is examined by Ryuhei Wakasugi and Banri Ito: do stronger intellectual property rights lead to higher technology transfer from multinational companies to their subsidiaries in developing host countries? Technology transfer decreases the production costs of the subsidiaries but risks spilling over to competing local firms. A theoretical three-stage game model under Cournot competititon predicts that technology transfer from the parent firm to the subsidiary increases with a strengthening of intellectual property

\footnotetext{
${ }^{1}$ The model is not included in the paper for reasons of space, but is available from the author upon request.
} 


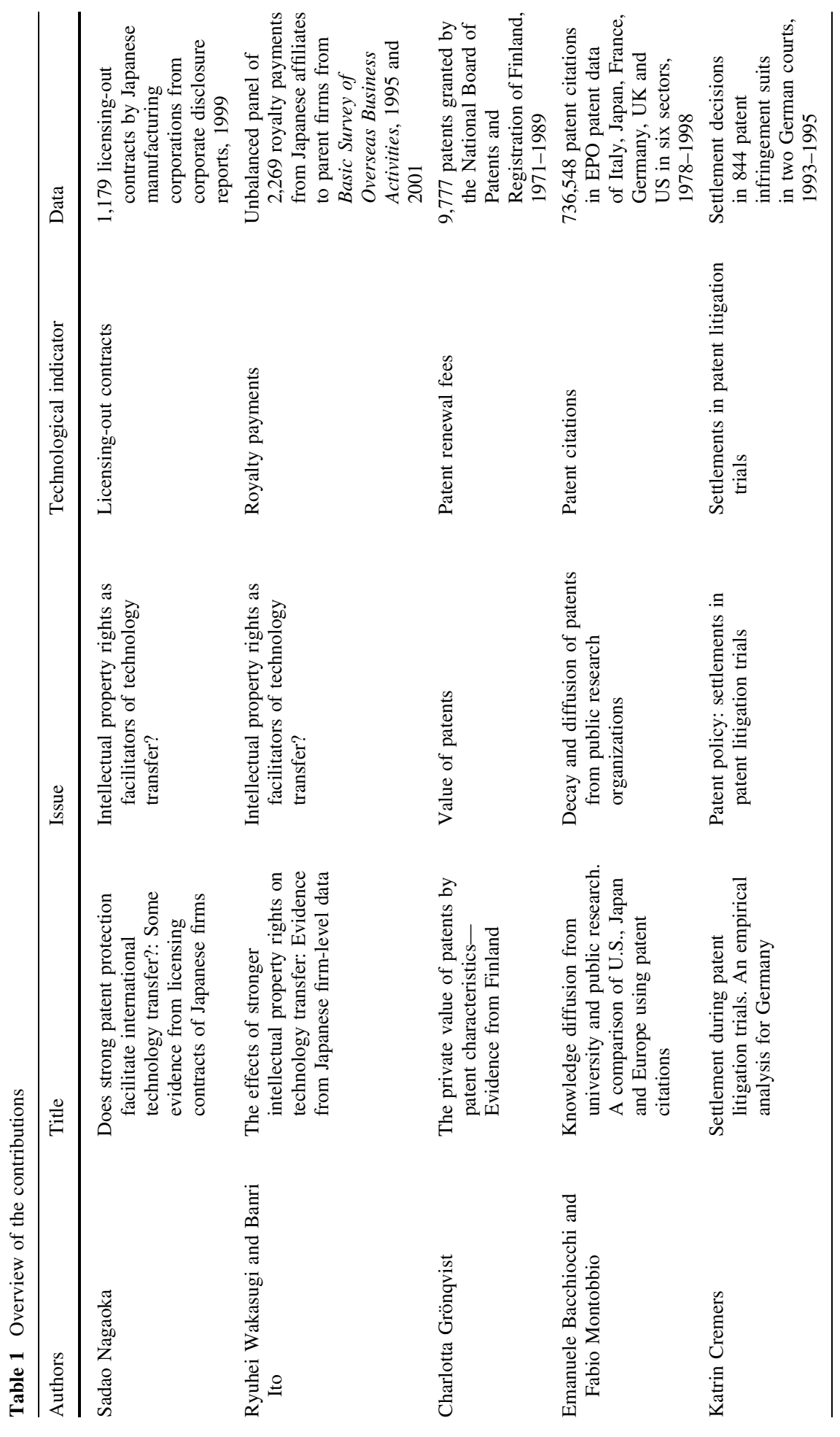




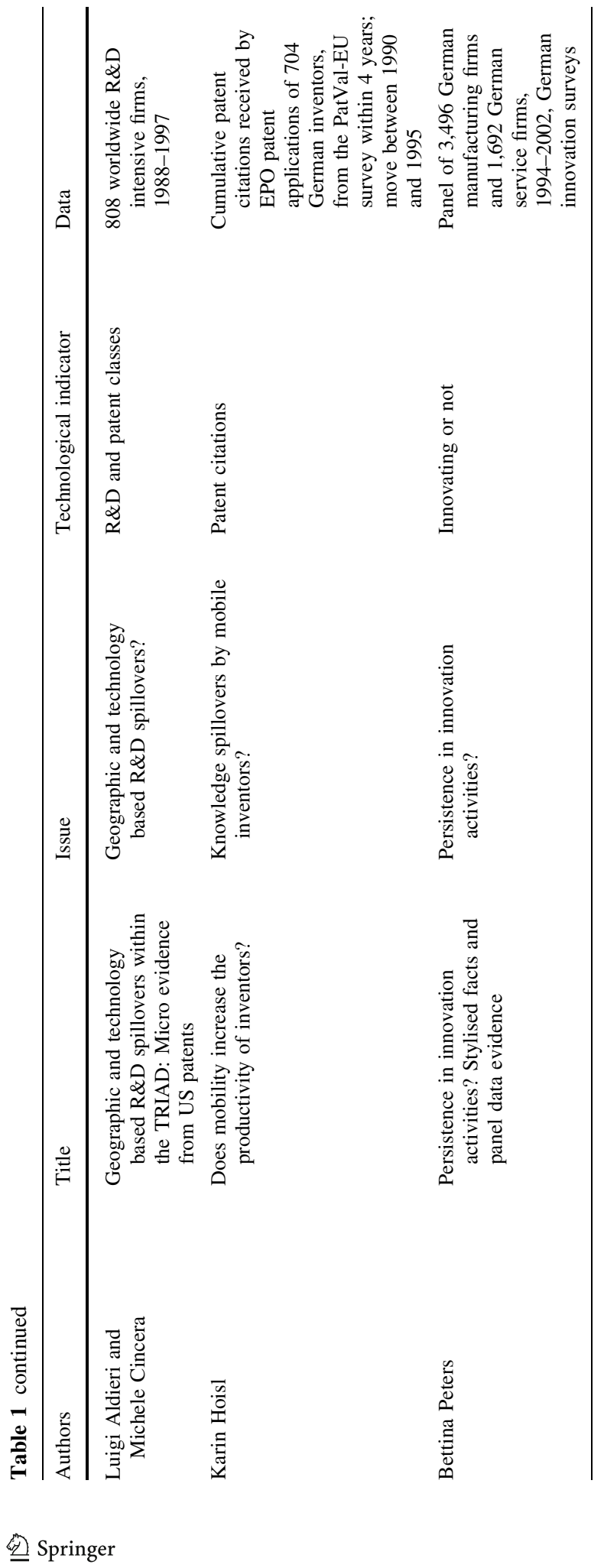


rights (IPR) if the technology transfer is above a certain level. The empirical part of the paper makes use of Japanese firm level panel data for two years regarding technology transfers from parents to their subsidiaries. After controlling for individual effects, host country specific effects, and parent specific effects it is found that an increase in the Park and Wagh IPR index in a host country is associated with a higher technology transfer between the Japanese parent firm and its subsidiary in this host country.

\section{Charlotta Grönqvist}

Charlotta Grönqvist estimates the value of all patents granted by the National Board of Patents and Registrations of Finland between 1971 and 1989 on the basis of patent renewal fees and renewal rates. She finds that there are large differences in mean value across technologies, that firm patents are more valuable than private patents, on average 1.5 times more, irrespective of technology and breadth, that broader patents are not necessarily more valuable than narrower patents, and that Finnish patent values are highly skewed. The decay rates appear to be pretty constant over the time period studied, but much higher in chemicals and electronics than in mechanicals, consumer goods and instruments. Narrower patents decay faster than broader patents. It is interesting to notice that renewing a patent for one more year signals that the patent is worth approximately 1.5 times more than if not renewed.

\section{Emanuele Bacchiocchi and Fabio Montobbio}

Emanuele Bacchiocchi and Fabio Montobbio estimate the rates of decay and diffusion of patents from university/public research organizations (PRO) and corporate patents using data from the EPO on patent citations. Six countries are compared: France, Germany, Italy, Japan, the UK and the US. PRO and university (in other words, public) patents tend to be cited more rapidly than corporate patents. However, the rate of decay of university and PRO patents is also higher than for corporate patents so that after a number of years they are cited less often than corporate patents. Also, there is a lot of heterogeneity across technological fields and countries. Actually, only in the US is there a significant difference in patent lag between corporate and university/PRO patents, which could be interpreted as a higher quality of public patents. No such thing is observable for the four largest European countries. Moreover, the superior fertility of university/PRO patents is restricted to certain fields such as chemicals, drugs and medicals, and mechanicals.

\section{Katrin Cremers}

In patent infringement litigation suits or license disputes, a settlement between the plaintiff and the defendant can take place at various stages of the trial procedure. Katrin Cremers uses a unique dataset of patent litigation suits, handled at two German District Courts (those of Düsseldorf and Mannheim), to estimate the marginal effects of the characteristics of the patent and the parties involved on the settlement rates at various stages of the trial.

The legal environment at the two District Courts has a significant effect on the settlement rate at different stages of the trial. The hearings are organized differently, and both plaintiffs and infringers regard the Düsseldorf District Court as more pro-patentee. It is 
only at later stages of the trial that invalidity suits and prior opposition have an effect (positive and negative, respectively) on the chances of reaching a settlement. Neither the absolute nor the relative size of the plaintiff matters. The number of claims in a patent increases the chances of reaching a settlement before the first oral hearing. The number of forward citations and the introduction of PCT applications increase the chances of reaching a settlement before the last stage of the trial.

\section{Luigi Aldieri and Michele Cincera}

Luigi Aldieri and Michele Cincera examine the nature and the extent of R\&D spillovers. Two measures of R\&D knowledge spillovers are contrasted: one is based on technological proximity (patenting in the same patent classes at the US Patent Office), and the other one is based on geographical proximity. The former is measured using Jaffe's (1986) uncentered correlation matrix between firms' US patent vectors across different patent classes, the latter uses the Haversine formula of geographical proximity based on latitudes and longitudes. Using a panel of 808 firms over a 10-year period from the Worldscope/Disclosure database, the authors find that total factor productivity growth is more sensitive to $\mathrm{R} \& \mathrm{D}$ spillovers than to the own $\mathrm{R} \& \mathrm{D}$ stock and more to technologically based than to geographically based measures of $R \& D$ spillovers. Only nearby located R\&D exerts any productivity enhancing spillovers, and the productivity effects of R\&D spillovers increase with the amount of own $R \& D$ (confirming the absorption capacity hypothesis).

\section{Karin Hoisl}

Karin Hoisl examines whether the move of an inventor (the first inventor listed on a patent document) from one employer to another leads to higher inventive performance, measured by the number of forward patent citations per patent application. A quantile regression framework is used to examine differences in the conditional distribution of inventive performance. The data are obtained from the PatVal survey of domestic inventors and from the EPOLINE database of the European Patent Office. Her results suggest that inventors move to improve the quality of their match with the employer, and by doing so they overtake the non-movers in the quality of their inventions. Especially inventors at the upper end of the conditional distribution are more able to catch up or to overtake their nonmoving control inventors. Multiple movers perform best.

\section{Bettina Peters}

Bettina Peters tests whether firms innovate persistently or discontinuously over time. She exploits a balanced panel of annual firm observations over the period 1994-2002 extracted from the German innovation surveys. Innovation is measured qualitatively by the occurrence of innovation expenditures, hence on the input side. She uses a dynamic random effects probit model, thereby controlling for individual effects to avoid spurious state dependence. The Wooldridge approach is used to account for the endogeneity of the initial conditions. Prior innovation activity, skills and individual unobserved heterogeneity are all found to be significant in explaining present innovation. Between one 
third and one half of the innovation persistence can be traced back to true state dependence (cleaned of observed and unobserved heterogeneity) in manufacturing and roughly $60 \%$ as much in services.

Open Access This article is distributed under the terms of the Creative Commons Attribution Noncommercial License which permits any noncommercial use, distribution, and reproduction in any medium, provided the original author(s) and source are credited. 